\title{
Research on Health Engineering for Communication System
}

\author{
Bin Chen ${ }^{1, a}$ and Juna $\mathrm{Li}^{1, a,{ }^{*}}$ \\ ${ }^{1}$ Electronic Engineering College, Naval University of Engineering, Wuhan, China \\ aLijuan770107@126.com
}

\begin{abstract}
Keywords: Health Engineering; Communication System; Health Lifecycle; Data Engineering; Communication Supporting
\end{abstract}

\begin{abstract}
To bear on the problems including the limited ability, sealed function and insufficient evidence of military communication organization, communication health engineering is proposed. Basing on requirements analysis for application background, the framework is built to achieve data acquisition, health assessment, fault diagnosis, intelligent decision for communication system with health as the core. Then, compatible to communication system engineering, the communication health lifecycle including the stages of research, requirement, analysis, development, $\mathrm{V} \& \mathrm{~V}$ and operation has represented. Various healthy activities have been recommended as well. From information perspective, data engineering has illustrated with data collection and transmission, data integration and fusion, and data application and service can achieve sensing, knowing and controlling of communication physical world. The presented study has shown that health engineering has feasibility and validity for communication supporting. The paper imposes health to the area of military communication. It is a technology innovation and will be translated into communication capability. Considerable military benefits will be obtained accordingly.
\end{abstract}

\section{Introduction}

Under the information and network battlefield environment, military communication system is the central nervous network in the modern warfare [1]. As information carrier, it can implement uninterrupted communication among all the elements of the battlefield to integrate all kind of supervisory system, intelligence system, command and control system, and firepower system which are scattered into space, sky, sea and land.

However, the existing communication system has several problems which cannot to be ignored. The limitations of comprehensive support may be caused because of knowing less of communication baseline state. The unknowns of system performance would lead to no reliable reference and means for deploying communication resources and assigning communication support task. These problems affect the communication system efficiency seriously.

Combining health monitoring technology and fault diagnosis technology, health management involves many subjects such as system engineering, automatic control, and domain knowledge. It can lay the theoretical and technical foundation for the scientific management of communication system. Study on health management has been started in the aerospace area. Aerospace Conference sponsored by IEEE Aerospace \& Electronics Systems Society has taken the health management system as a research topic where can be found a large number of relevant documents. Subsequently, Health management has developed rapidly in many field including national defense, military, transportation and other industries. Series of results have been obtained and the related theories are becoming more and more mature [2-4]. The typical research achievements are including Integrated System Management (ISHM), Complex System Health Management (CSIHM), Prognostics and Health Management (PHM) [5-7].

Guided by system health management [8-10], health engineering can be implemented for communication system. With health running through the whole process of the communication system lifecycle, it will provide advanced theoretical support and technical means for communication system management. Further, it can provide strong support to enhance the military communication capability. 


\section{Requirement Analysis}

Many particular requirements are specified for military communication system as the following. First, it should have the ability to perform all kinds of communication from long distance to short distance. Second, it should provide enough, stable and reliable communication lines for all scenarios including shore, sea, sky and underwater. Third, it should give right communication mode applied in harsh environment. Fourth, it should use advanced communication technology against strong electromagnetic interference. Fifth, it should have strong compatibility and interoperability to support multi-arms cooperative engagement.

Accordingly, military requirements of communications system health are listed below.

Needs of arrangement for communication duty

Operation quality and work efficiency of the communication system should be calculated, analyzed and predicted. Baseline ability and operational effectiveness indicated by remaining useful life, the attenuation of technique condition, system reliability etc. should be mastered and predicted effectively. The service quality of various communications business should be perception in real time and prejudgment availably.

Needs of plans for communication organizing and tailoring

The status of communication system technology baseline such as number of communication equipment and integrity information should be grasped accurately. Detailed communication information involving independent elements, equipment state and relevant resource should be summarized and integrated. Resources allocation scheme, communication organization pre-arranged planning and communication business programming should be evaluated and further optimized.

Need for communication organizing and adjustment

The resource state and executive capacity of communication system deployed should be understood in real time which provides the support for dynamic communication organizing. The performance of communicating supporting in the certain area should be controlled effectively when the communication organization is been conducting dynamically. The actual achievement of communication services should be comprehended while communication project is adjusted.

\section{Health Framework}

Flow of Health Analyzing. The communication system health can be defined as the ability providing to maintain oneself normal function which is an important guarantee for system reliability. Fault management is the core of the communication system health from the perspective of operability.

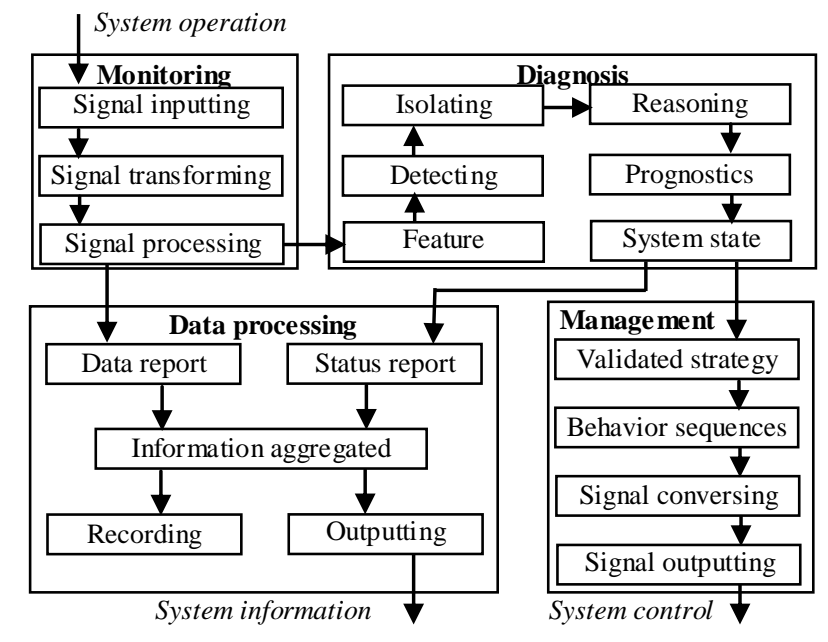

Figure 1. Finite Flow of health analyzing for communication system

Focusing on the fault, the flow of health analyzing for communication system is depicted in Fig. 1 There are four parts involved which consist of monitoring, diagnosis, management and data 
processing. The monitoring segment would get the basic date of the system state by the steps of signal inputting, signal transforming and signal processing, and then will produce the data report. On this basis, the diagnosis segment can implement fault detecting, fault isolating and reasons analyzing after feature extraction. Accordingly, system state and prognostics can be understood well and the status report for the whole communication system would be produced. Consequently, the management segment will design and validate the strategy with several behavior sequences. Thus, system control can be performed by signal conversing and signal outputting. Meanwhile, the data report and the status report would be aggregated in data processing segment where the system information is output and recorded.

During the process created, the analysis and optimization in system-wide are carried on to determine communication health state. Therefore, the health engineering for communication system would be developed to achieve stable and reliable ability of system health.

Structure of System Health. The core of communication system is to identify and manage faults from the perspective of system. The system health and effective communication supporting will be guaranteed by avoiding, alleviating and eliminating system faults in time. According to the requirement of communication health, the structure of system health is abstracted as shown in Fig. 2, which including data acquisition, health assessment, fault diagnosis, intelligent decision and interface system.

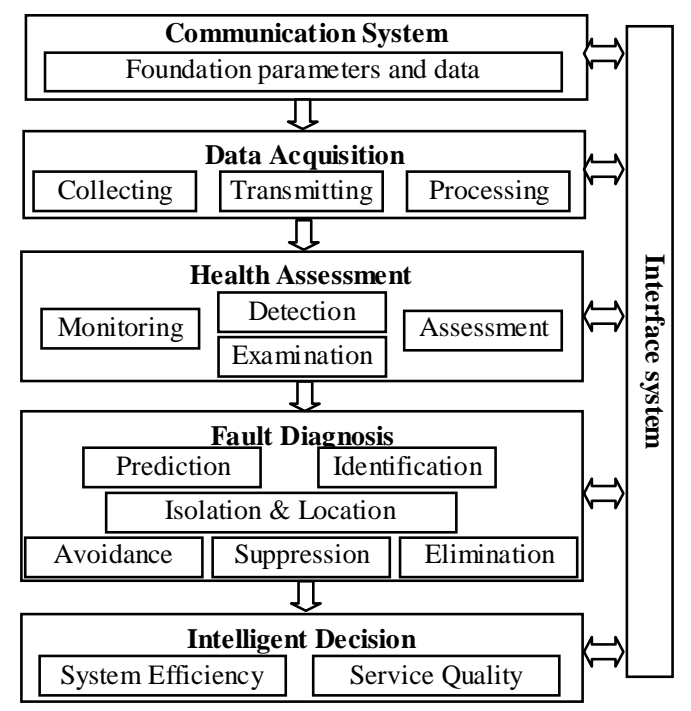

Figure 2. Finite Structure of communication health

Data acquisition system can collect all the foundation parameters and data involved. Data transmission and data processing are also contained to provide comprehensive, standardized and normalized data. The health assessment system which consisted of state monitoring, anomaly detection, health examination and health assessment can achieve health examination and anomaly detection to evaluate the health status of the system and components inside. The fault diagnosis system can achieve fault avoidance, fault suppression or failure elimination as much as possible after forecasting or recognizing fault and then carrying out fault isolation and location. The intelligent decision system can estimate system efficiency and service quality for the specific tasks and requirements in communication support intelligently.

The interactive functions will be provided by the interface system. It includes the interaction with other systems, the interaction among internal modules and the interaction with humans.

\section{Process of Health Engineering}

Health and System Engineering. The communication system is the executive object of health engineering. The health is a dynamic property throughout all process of the communication system life cycle. So, it is interwovenness between communication health engineering and communication 
system engineering. The communication system engineering life cycle is can be divided into the concept stage, developing stage, producting stage, using stage, maintenance stage and sunsetting stage. The tasks of system engineering and communication health in every stage are shown in Table1.

Table 1 Communication Engineering Task

\begin{tabular}{|l|l|l|}
\hline Stage & System Engineering Task & Health Task \\
\hline Concept & $\begin{array}{l}\text { Formulating preliminary system } \\
\text { requirements and feasible design } \\
\text { proposal }\end{array}$ & $\begin{array}{l}\text { Health } \\
\text { requiring }\end{array}$ \\
\hline Developing & $\begin{array}{l}\text { Planning and designing the } \\
\text { application system meeting } \\
\text { communication requirements }\end{array}$ & $\begin{array}{l}\text { Health } \\
\text { designing }\end{array}$ \\
\hline Producing & $\begin{array}{l}\text { Making, testing and verifying of } \\
\text { products and related supports }\end{array}$ & $\begin{array}{l}\text { Health } \\
\text { achieving }\end{array}$ \\
\hline Using & $\begin{array}{l}\text { Running to perform various } \\
\text { communications missions }\end{array}$ & $\begin{array}{l}\text { Health } \\
\text { monitoring }\end{array}$ \\
\hline Maintenance & $\begin{array}{l}\text { Providing maintenance and other } \\
\text { services to ensure the normal } \\
\text { operation }\end{array}$ & $\begin{array}{l}\text { Health } \\
\text { ensuring }\end{array}$ \\
\hline Sunsetting & Scrapping treatment & None \\
\hline
\end{tabular}

From the point of system engineering, health engineering for communication system is an essential aspect of the system engineering. System management, project activities and crossdepartment cooperation should be carried on focusing on the system health. Moreover, communication system health can be designed as an individual system due to its own characteristics of functionality, systematicness and relative independentability. From this perspective, health engineering should consider and integrate each subsystem in the communications system because the role of the health is across multiple subsystems. System health would be influenced by varies subsystems or their relation.

Communication Health Lifecycle. Obviously, communication health engineering is consistent and compatible to communication system engineering. Similarly, the healthy lifecycle of communication system is shown in Fig.3 The measure of detection and control should be considered in each stage throughout the whole health lifecycle. Meanwhile, iteration and feedback are existed between varies stages in communication health engineering.

The main operation and task in each stage are shown in Table 2.Scientific research should be done to identify and improve techniques and methods for communication system operation and maintenance in research stage. It provides technology supporting and theoretical principle for developing advanced communication health. The main task in the requirement stage is requirement analysis. Communication health requirements should be effectively evolved in the communication healthy development to ensure the achievement of the desired goal. In analysis stage, system analysis is carried out focusing on the communication health requirement. The primary communication health and the detailed implementation project should be designed supporting by minute function analysis. In development stage, detailed design of communication health should be done and then communication health solutions should be developed to satisfy all health requirements. 


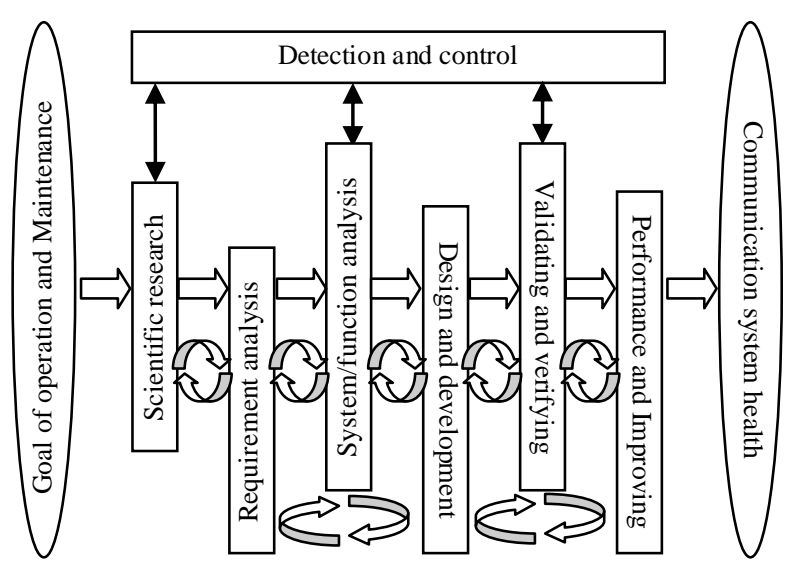

Figure 3. Finite Healthy lifecycle of communication system

Table 2 Operation and Task in Health Lifecycle

\begin{tabular}{|c|c|c|}
\hline Stage & Operation & Task \\
\hline Research & $\begin{array}{l}\text { Basic research on } \\
\text { communication } \\
\text { health science }\end{array}$ & $\begin{array}{l}\text { Technology } \\
\text { supporting }\end{array}$ \\
\hline Requirement & $\begin{array}{l}\text { Requirements analyzing } \\
\text { to define } \\
\text { communication health } \\
\text { requirements and } \\
\text { consider how to evolve } \\
\text { them in constructing, } \\
\text { testing and operating } \\
\text { process }\end{array}$ & $\begin{array}{l}\text { Making } \\
\text { communication } \\
\text { health requirements }\end{array}$ \\
\hline Analysis & $\begin{array}{l}\text { System and function } \\
\text { analyzing to understand } \\
\text { how system } \\
\text { components effect on } \\
\text { the communication } \\
\text { health }\end{array}$ & $\begin{array}{l}\text { Drafting the primary } \\
\text { communication } \\
\text { health project and } \\
\text { building } \\
\text { conceptual } \\
\text { framework }\end{array}$ \\
\hline Development & $\begin{array}{l}\text { Detailed designing and } \\
\text { realizing the } \\
\text { communication health } \\
\text { solutions }\end{array}$ & $\begin{array}{l}\text { Developing } \\
\text { satisfactory solutions } \\
\text { for communication } \\
\text { health }\end{array}$ \\
\hline $\mathrm{V} \& \mathrm{~V}$ & $\begin{array}{l}\text { System testing in the } \\
\text { environment as possible } \\
\text { to actual operating } \\
\text { conditions to validate } \\
\text { and verify } \\
\text { communication health }\end{array}$ & $\begin{array}{l}\text { Validating and } \\
\text { verifying } \\
\text { communication } \\
\text { health }\end{array}$ \\
\hline Operation & $\begin{array}{l}\text { Improving according to } \\
\text { communication system } \\
\text { actual performance }\end{array}$ & $\begin{array}{l}\text { communication } \\
\text { health maintenance }\end{array}$ \\
\hline
\end{tabular}

In $\mathrm{V} \& \mathrm{~V}$ stage, the reasonable test should be done many times under the environment as possible to actual operating conditions to demonstrate that the communication system health solution has met all health requirements. Actually, the validating and verifying process has already begun. The requirement validation has done basing on the early analysis. The validation and analysis in the 
various aspects of reliability, safety and fault handling have conducted beginning in the development stage. It will help to understand the health project and the corresponding evaluation and management.

Because of the technical limitations, the defects of the system design cannot be completely avoided. So, it needs to be further improved according to the communication system operation in the operation stage.

Communication Health Timeline. Each stage of communication health project engineering can be incorporated into the process of communication system engineering. Communication health lifecycle is coincident with communication system engineering in time and process. The roughly corresponding relationship is shown in Fig. 4.

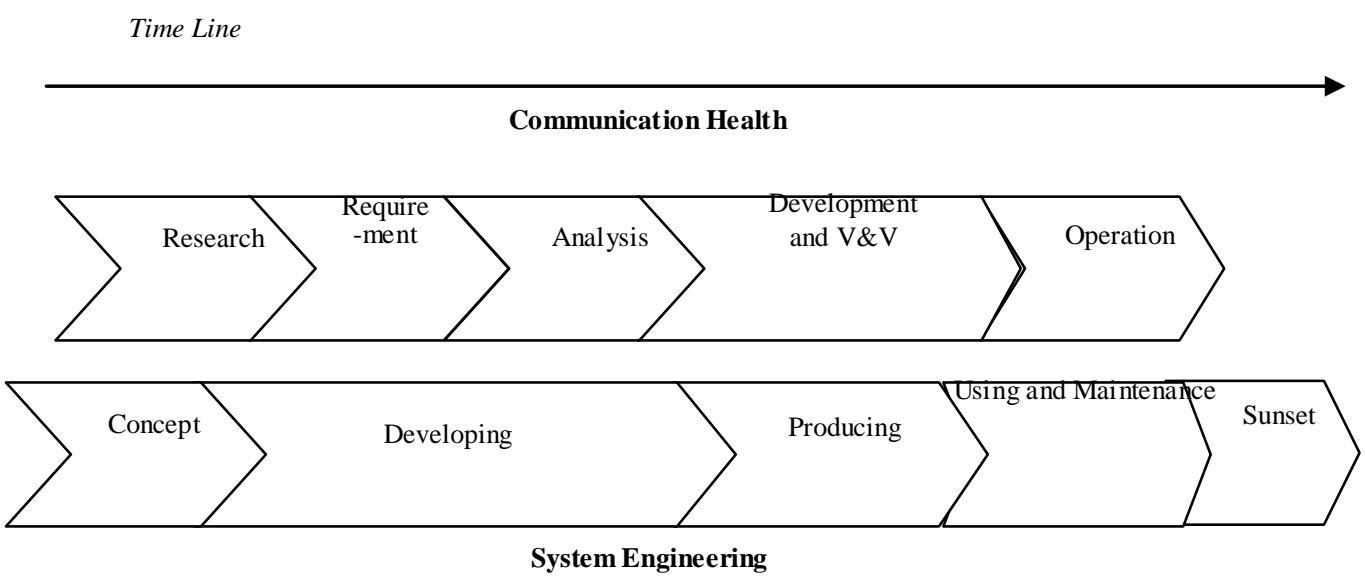

Figure 4. Finite Time Line of communication system

Ideally, communication health engineering should be begun at the start of communication system engineering. The tasks in every stage of communication health engineering are also existed in the communication system engineering. Communication system engineering should consider health issues. Meanwhile, communication health engineering would provide health services for communication system.

\section{Data Engineering of Communication Health}

As it were, the health of communication system fuses information space with physical space in communication field with information interaction of things-things and people-things as core. From view of the information, the flow of information in the communication health is shown in figure 5. Information acquisition proportion would collect data in communication physical space overall. The data acquired should be sent to information processing unit. The strategy information will be generated after intelligent processing. It then can give necessary behavioral control to the communication physical space by the information implement section.

The data engineering of communication system strives to achieve the free flow of data information apperceived from objective world in the communication field. Information collection and transmission, information integration and fusion, and information application and service are involved according to sensing, knowing and controlling of communication physical world.

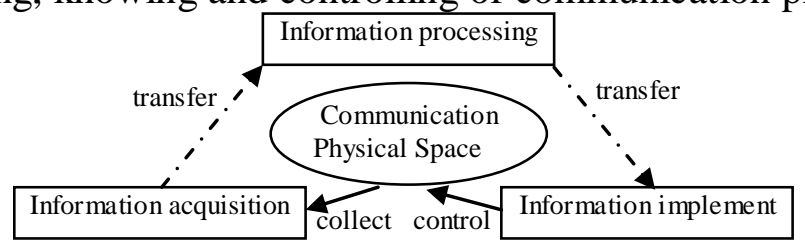

Figure 5. Finite Time Line of communication system 
In the data engineering of communication system, data is the initial form for expressing the health of communication system which reflects the objective phenomena of the communication physical world. Next, the information is obtained in the form of structured data. Then, the knowledge will be formed after feature abstraction and cognition. Last, the communication wisdom will achieve which can generate decision and control information to guide communication operation intellectually.

\section{Conclusion}

Military communication system is a multi-dimensions information network of land, sea and air to support the modern military activity. However, it doesn't always work so effectively as expectations because of the limited supporting ability, sealed system function and insufficient evidence for communication organization. Communication health engineering is proposed aiming to these defects.

Taking health as the core, communication health engineering will implement communication system management and maintenance to achieve data acquisition, health assessment, fault diagnosis, intelligent decision for communication system. During communication health lifecycle, various healthy activities will be done surrounding communication health. From view of the information, data engineering for communication health can achieve sensing, knowing and controlling of communication physical world. Communication health is a beneficial engineering for military communication system. It will provide strong support to enhance the military communication capability.

\section{References}

[1] Gao Xiaoling, Liu Zuoxue, and Du Gang. The foundation of military communication command, National Defence Industry Press, Beijing, 2013

[2] Li Xiangqian. Research on Key Technology of Fault Prognostic and Health Management for Complex Equipment, Beijing Institute of Technology, Beijing, 2014.

[3] Pei Daming, Wang Jianfeng, and Zhou Pengtai. "Survey on PHM technology in marine system," Journal of Electronic Measurement and Instrumentation, vol. 30, September 2016, pp. 1289-1297.

[4] Wang Min. Research on Fault-Diagnosis Knowledge Acquisition Methods for Health Management of Key Subsystems of Flight Vehicle, National University of Defense Technology, Changsha, 2013.

[5] Hu Shaolin, Zhao Gang, and Guo Xiaohong. "Review on Spaceflight Safety and Health Management," Journal of Shanghai Institute of Technology(Natural Science), vol. 15, March 2015, pp. 286-292,298.

[6] Lv Chen, Ma Jian, and Wang Zili. "A state of the art review on PHM technology," Computer Measurement \& Control, vol. 24, September 2016, pp. 1-4.

[7] Qi Ziyuan, Zhang Jinqiu, and Ma Zhao. "Research on the structure and key technologies of equipment fault prediction and health management system," Artificial Intelligences \& robotics Research, vol. 02, April 2013, pp. 95-100.

[8] SB Johnson. The Theory of System Health Management, John Wiley \& Sons, Inc. New Jersey, 2013.

[9] Jing Bo, Tang Wei, and Huang Yifeng. "Summary of PHM system standards," Journal of Electronic Measurement and Instrumentation, vol. 27, December 2014, pp. 1301-1307.

[10] Zhang Jinyu, and Zhang Wei. Intelligent fault diagnosis and prediction of equipment, National Defence Industry Press, Beijing, 2013. 